\title{
EFFECT OF HIGH TEMPERATURES ON CEMENT COMPOSITE MATERIALS IN CONCRETE STRUCTURES
}

\author{
Lenka BODNÁROVÁ ${ }^{1)^{*}}$, Jaroslav VÁLEK ${ }^{1)}$, \\ Libor SITEK $^{2)}$ and Josef FOLDYNA ${ }^{2)}$
}

\author{
1, Brno University of Technology, Faculty of Civil Engineering, Institute of Technology of Building Materials and \\ Components, Veveři 95, 60200 Brno, Czech Republic \\ 2) Institute of Geonics of the ASCR, v.v.i., Studentská 1768, 70800 Ostrava-Poruba, Czech Republic \\ *Corresponding author's e-mail: bodnarova.1@fce.vutbr.cz
}

(Received July 2012, accepted March 2013)

\begin{abstract}
Concrete is flexible construction material, which is utilized in various technological applications for underground structures and reinforcement of mine works (adits, tunnels etc.). In such applications, concrete has many functions - static function, water-tightness, gas-tightness, resistance to action of aggressive waters as well as durability. In case of railroad and road tunnel constructions, there is another important problem: influence of high temperatures on concrete lining during wildfire. The paper focuses on analysis of behavior of cement composite material (concrete) exposed to high temperatures. Several possibilities of increasing resistance of cement composites to high temperatures are proposed as well as recommendation for reduction of damage on structures exposed to high temperature.
\end{abstract}

KEYWORDS: high temperature, load resistance, concrete, reinforcing of mine works, fiber reinforcement

\section{INTRODUCTION - USE OF CONCRETE IN UNDERGROUND STRUCTURES}

Concrete as a construction material can have various specific properties (self-compacting concrete, high-strength concrete, direct-finish concrete, fastsetting concrete, shotcrete etc.). As a versatile material, it is widely used also in underground construction industry, especially for construction of railroad and road tunnels. At this case, two stages of the construction are often utilized. First, concrete as primary lining in the form of sprayed one, which is applied directly on stope in rock. Such concrete has to have specific properties: it should be fine-grained concrete mostly with addition of dispersed reinforcement and setting accelerators. At the second stage, concrete is used for concreting of secondaryfinal lining of the tunnel. Since concrete at this stage is placed by pumping into formwork and thickness of layer is variable, its rheological properties are very important. Moreover, after removing formwork, surface of the secondary lining is the face of inner walls of the tunnel. This fact increases requirements for appropriate composition of the concrete mixture.

Apart from construction of railroad, road and subway tunnels, concrete in underground construction industry can be applied for civil and industrial constructions, for construction of basement structures (foundations, base plates, piles) and for direct construction of underground structures (underground garages, basements, so-called white basins etc.). Construction of underground collectors is another case, where the only material used is concrete. However, concrete for such structures is mostly in the form of prefabricated elements.

\section{BEHAVIOUR OF CONCRETE AT HIGH TEMPERATURES AND POSSIBILITIES OF INCREASING RESISTANCE OF CEMENTITIOUS CONCRETE TO HIGH TEMPERETAURES}

Road traffic keeps growing, which brings higher number of road accidents in road tunnels. This increases the requirements of high temperature resistance of tunnel lining because the thermal resistance is one of the important behaviours of the construction (Hanzlíček and Perná, 2011). Final surfaces of most of road tunnels are finished concrete walls. Therefore, concrete walls are directly exposed to action of high temperatures during fire. Concrete structures with higher resistance to high temperatures imply higher demands on individual components of concrete. Cement is of course the most important part. However, other components are also important: aggregate, types of admixtures and additives, method of reinforcement, addition of polypropylene fibres and steel wires. 
Temperature during fire which destroys concrete structure in road tunnel can be as high as $1200{ }^{\circ} \mathrm{C}$. The main questions of influence of high temperature on concrete involve complex identification of changes in cement matrix and study of transport phenomena (Zeiml et al., 2008). Analysis is rather complicated because cement based concrete is composite material consisting of two very different components: mastic cement and aggregates. Moreover, various types of aggregate have different mineralogical composition. Minerals exposed to high temperature show metamorphic changes, which are typical and different for each mineral.

Impact of fire on concrete causes decrease of its quality. The whole structure of cement paste degrades and the bearing capacity decreases rapidly. The rate and mode of concrete degradation and destruction of whole concrete structure depends on the type of fire, the rate of rise in temperature and duration of the fire. The most important premise in prediction of concrete stability is to ascertain the types of fire which could occur in tunnel and underground spaces. The research in this field was oriented to behaviour of concrete in real tunnels, disused tunnels as well as in laboratory conditions. Series of time/temperature curves for the various exposures have been developed based on data obtained from these tests. For example hydrocarbon fire is defined as a fire in road tunnels, where heavy lorries transporting inflammable and volatile liquids above 4 ton of weight catch fire (EN 1992-1-2 Eurocode 2). Intensity of such a fire is characterized by the power of $10-100 \mathrm{MW}$. In the past, accidents occurred in road tunnels resulting in fires causing spalling of concrete even though the intensity of fire was lower than that of standard hydrocarbon fire. Three important fires took place in the Great Belt Tunnel in 1994, Channel Tunnel in 1996 and Mont Blanc Tunnel in 1999. Fire in Great Belt Tunnel caused considerable spalling of concrete in some sections of the tunnel. Heat of fire in Channel tunnel reached $700{ }^{\circ} \mathrm{C}$, which decreased the thickness of tunnel lining to $400 \mathrm{~mm}$, at some places even down to the critical value of $200 \mathrm{~mm}$. This resulted in closing down the tunnel for 6 months and loss of 1.5 million dollar per day, regardless of the cost of repair (Kodur, 2008). Following important fires in road tunnels from recent time are worth mentioning: Austrian tunnel Kaprun in 2000 and Italian - Swiss Frejus Tunnel in 2005. On 30th October 2005, an extensive fire started in Limehouse Link Tunnel Central London, caused by flashing of a bus, the intensity was around 30 MW. Temperature development curve of each fire is different. For testing of thermal load of concrete used for road tunnels, "the most rigorous" RWS (Rijkwaterstaat) thermal development curve is usually used. The RWS curve was developed by the Rijkswaterstaat, Ministry of Transport in the Netherlands. The RWS curve simulates the initial rapid growth of a fire using a petroleum tanker as the source, and the gradual drop in temperatures to be expected as the fuel load is burnt off (Fire design of concrete structures: materials, structures and modelling, FIB, No 38, 2007).

\subsection{EFFECT OF HIGH TEMPERATURE ON CEMENT PASTE}

Heating of cement paste causes evaporation of various water types presented in material. Water gets gradually loose from the material. First, free water from cement paste evaporates through capillaries and then chemically bounded water leaves the material (Meftah et al., 2012). Nevertheless, hydrothermal reaction can occur causing considerable physical and chemical changes in microstructure (internal autoclaving) if cement paste is heated in enclosed and humid environment. Character of phase changes depends on several aspects: the mineralogical composition of cement, $\mathrm{Ca} / \mathrm{SiO}_{2}$ ratio, the amount of fine elements (quartz or silica fume), and level of both temperature and pressure.

Mechanical properties of cement paste are strongly influenced by chemical bonds and their strength between sheets of C-S-H (calcium silicate hydrate) gel. It is assumed that about $50 \%$ of the cement paste strength is provided by bond strength (huge C-S-H gel sheet area). Evaporation of water taking place between sheets of $\mathrm{CSH}$ gel strongly influences mechanical properties of cement paste. Dehydration process of C-S-H gel causes decrease of volume of hydrates, which increases porosity of cement matrix. Total volume of pores grows; consequently average size of pores grows, too. Strain in cement paste is a result of strain of its components: shrinking hydrated phases and expanding nonhydrated phases. Cement paste expands around 200 ${ }^{\circ} \mathrm{C}$, while it shrinks intensively after exceeding this temperature (Feldman and Sereda, 1968), (Ellis, 1999).

Calcium aluminate cements show the highest level of resistance to high temperatures. However, such cements have only limited application nowadays; they are used mainly for special purposes. Calcium aluminate cement is used for example for refractory concrete used for monolithic furnace lining. Calcium aluminate cement is mostly not recommended for construction concrete. The reason of the forbiddance is the fact, that conversion process (change of metastabile phases $\mathrm{CAH}_{10}$ and $\mathrm{C}_{2} \mathrm{AH}_{8}$ to stabile cubic $\mathrm{C}_{3} \mathrm{AH}_{6}$ ), which can last several years depending on surrounding temperature, causes increase of porosity and decrease of strength. That is why content of calcium aluminate cement in concrete should be at least $400 \mathrm{~kg} \cdot \mathrm{m}^{-3}$ and water cement ratio should not exceed the value of 0.40 to limit the phenomenon of conversion (EN 14647).

Besides concrete with ordinary Portland cement CEM I and calcium aluminous cements, influence of high temperatures on the concrete with blended cements CEM II, blast furnace cement CEM III, pozzolanic cement CEM IV and composite cement 
CEM V (according to EN 197-1) is studied, too. The research is focused on all main constituents. Cements with fly ash (Khandaker, 2006), pozzolana (Savva et al., 2005), limestone etc. are studied.

Ordinary Portland cement is the least suitable hydraulic binder for high temperature exposition, because it decays after loss of chemically bound water in hydration products. Thanks to chemical and mineralogical composition, portlandite is among the dominant products of cement hydration. The effect of temperature leads to decomposition of portlandite at interval approximately from 450 to $550{ }^{\circ} \mathrm{C}$. This reaction can be described by the equation

$$
\mathrm{Ca}(\mathrm{OH})_{2} \rightarrow \mathrm{CaO}+\mathrm{H}_{2} \mathrm{O} .
$$

The increase of porosity of cement matrix and the decrease of its strength parameters are the results of the decomposition reactions. This has naturally inapt effect on mechanical properties of whole concrete. However, hydration process can be modified if concrete contains admixture demonstrating socalled pozzolanic properties. Mainly calciumhydrosilicate gels are the products of hydration in this case. These phases are disintegrated in relatively wide range of high temperatures. Residues of calciumhydrosilicate phases can be identified also in the matrix exposed to temperature from 600 to $700{ }^{\circ} \mathrm{C}$. That is why matrix modified by pozzolanic admixtures demonstrates higher resistance to high temperatures in comparison with the matrix based on pure portland cement. Therefore, it is better to use blended cement with lower content of Portland clinker and more additions based on fly ash or slag.

\subsection{EFFECT OF HIGH TEMPERATURE ON AGGREGATE}

Aggregate, like nearly all solid substances, expands with increasing temperature. Therefore, thermal expansion of aggregate is an important property as regards influence of higher temperatures. Thermal expansion of aggregate depends on its mineralogical composition; value of thermal expansion of each mineral is different. Suitable aggregate for high temperature resistant concrete has to prove low coefficient of thermal expansion and negligible residual strain. Metamorphic changes of minerals like change of quartz at temperature of $574{ }^{\circ} \mathrm{C}$ can be also presented. This change causes increase of volume by approximately $0.84 \%$. Carbonate aggregate such as limestones and dolomites are stable up to about $700{ }^{\circ} \mathrm{C}$ when the $\mathrm{CaCO}_{3}$ calcium carbonate decomposes into lime $\mathrm{CaO}$ and $\mathrm{CO}_{2}$. When cooling, the $\mathrm{CaO}$ can hydrate producing expansion of $40 \%$. Examples of the large range of thermal stabilities and processes taking place in the commonly used both natural and artificial aggregates during heating were published by Khoury (Khoury, 1992). The effect of different types of aggregates was also studied for example in the work of Savva (Savva,
2005), where author examined influence of elevated temperatures on the mechanical properties of concretes prepared with limestone and siliceous aggregates. Relative residual compressive strength after heating to $750{ }^{\circ} \mathrm{C}$ was slightly higher in concrete with siliceous aggregates $(0.25 \%$ on average using various types of blended cement).

Natural aggregate must not change its mechanical properties; primarily it must not lose its compressive strength and must not show changes in volume at higher temperatures. Aggregates that are thermally stable up to a given temperature show no weight loss, no thermal reactions and negligible residual strain. Basalt, diabase and andesite are the most suitable natural rocks. Silicic aggregate and granite are the least suitable rocks. Silicic aggregate cracks and granite shrinks excessively when exposed to high temperature. Limestone turns out to be surprisingly suitable for high temperatures, because changes caused by temperatures above $500{ }^{\circ} \mathrm{C}$ limit only to thin surface layers, which protect the core very well. For reasons of reaction of aggregate to high temperature, suitable aggregate for concrete would be that with low coefficient of thermal expansion and negligible residual strain, which are the properties that limestone shows. It is not recommended to use aggregate with various thermal conductivity (Fib Bulletin 38, 2007). That is why artificial aggregate must be used for concrete structures, which are likely to be exposed to temperatures of $700{ }^{\circ} \mathrm{C}$ or higher. For temperatures above $1000{ }^{\circ} \mathrm{C}$ crushed fireclay, corundum, carborundum, crushed bauxite or chromite can be used as aggregates.

\subsection{DISPERSED REINFORCEMENT}

One of the ways how to increase fire resistance and reduce spalling of concrete is addition of polypropylene fibers. Application of polypropylene fiber can moderate destructive effect of expanded water vapor. Melting point of polypropylene lies between $100-200{ }^{\circ} \mathrm{C}$. At such temperatures, polypropylene fibers evaporate from concrete and form small cavities inside concrete. Structure of concrete becomes more porous and expanded water vapor can escape without substantial damage of concrete microstructure. This effect limits development of cracks in the concrete structure and spalling of surface layers. It was proved that fibers with higher slenderness ratio are more suitable. Porous structure of concrete is then more interconnected and expanded water vapor has easier way to escape without damaging the concrete (Hager and Tracz, 2009; Pistol et al., 2012).

\section{EXPERIMENT}

\subsection{METHOD OF EXPERIMENTAL WORK}

The aim of experimental work was to design and test mix-designs with higher resistance to high temperatures. First of all, input materials were 
selected based on research of accessible knowledge and former work (Bodnárová, 2010). At the first stage, mix-designs were adjusted and tested with respect to appropriateness of composition and rheological properties. For the following testing, 5 mix-designs were selected, four of them with components aimed at enhancing properties of concrete exposed to high temperatures. Manufactured concrete specimens were exposed to thermal load of $200{ }^{\circ} \mathrm{C}$, $400{ }^{\circ} \mathrm{C}, 600{ }^{\circ} \mathrm{C}$ and $900{ }^{\circ} \mathrm{C}$ in a stove with isothermal dwell of 60 minutes after 28 days of maturing. Then basic physical-mechanical properties were determined (density, compressive strength) and compared to test results of specimens not exposed to thermal load.

Surfaces of specimens exposed to thermal load were analyzed and percentage of damage was determined. Method of surface analysis to determine percentage of cracks on tested specimens was based on Xing Zhi (Xing Zhi, 2011). Method used in this paper for determination of damaged area of tested specimen (area of cracks) and for comparison with total area utilises the AutoCAD software. High resolution images were imported, zoomed to maximal resolution and cracks were marked as individual areas. Then the sum of areas of cracks related to total area of tested specimen was calculated.

\subsection{MIX-DESIGNS}

Blended Portland cement CEM II/B-M (S-LL) $32.5 \mathrm{R}$ was used for manufacturing of every tested mixture. Chemical composition of used cement is specified in Table 1.

Reference mix-design contained commonly used aggregate from around the city of Brno (Czech Republic): $0-4 \mathrm{~mm}$ quartz sand (Náklo), $4-8 \mathrm{~mm}$ carboniferous greywacke (Olbramovice) and $8-$ $16 \mathrm{~mm}$ carboniferous graywacke (Olbramovice). For other mix-designs, resistant basalt aggregate (Bílčice) was used.

Table 2 Composition of individual mix-designs (REC).
Table 1 Chemical composition of cement CEM II/BM (S-LL) 32.5 R.

\begin{tabular}{cc}
\hline Component of cement & \% of total \\
\hline $\mathrm{SiO}_{2}$ & 19.37 \\
$\mathrm{Al}_{2} \mathrm{O}_{3}$ & 4.31 \\
$\mathrm{Fe}_{2} \mathrm{O}_{3}$ & 2.66 \\
$\mathrm{CaO}$ & 61.14 \\
$\mathrm{MnO}$ & 0.16 \\
$\mathrm{TiO}_{2}$ & 0.26 \\
$\mathrm{MgO}$ & 2.10 \\
$\mathrm{~K}_{2} \mathrm{O}$ & 0.73 \\
$\mathrm{Na}_{2} \mathrm{O}$ & 0.16 \\
$\mathrm{SO}_{3}$ & 2.55 \\
$\mathrm{Cl}$ & 0.064 \\
$\mathrm{P}_{2} \mathrm{O}_{5}$ & 0.12 \\
$\mathrm{Loss}_{3}$ of ignition & 8.98 \\
\hline
\end{tabular}

To increase resistance to high temperature, polypropylene fibers (hereinafter referred to as PP) and natural cellulose fibers were used. Following fibers were tested: PP fibers A (PP, length $3 \mathrm{~mm}$, diameter $5 \mu \mathrm{m}$, melting point $160{ }^{\circ} \mathrm{C}, \rho=910 \mathrm{~kg} \cdot \mathrm{m}^{-3}$, tensile strength $370 \mathrm{~N} . \mathrm{mm}^{-2}$ ), PP fibers B (PP, length $12 \mathrm{~mm}$, diameter $28 \mu \mathrm{m}$, melting point above $160{ }^{\circ} \mathrm{C}$, $\rho=910 \mathrm{~kg} \cdot \mathrm{m}^{-3}$, tensile strength $320-400 \mathrm{~N} \cdot \mathrm{mm}^{-2}$ ) and Ultra Fiber 500 Buckeye (cellulose, $5 \mathrm{~mm}$ x $6 \mathrm{~mm}$ chip, fiber length $2.1 \mathrm{~mm}$, diameter $18 \mu \mathrm{m}$, $\rho=1100 \mathrm{~kg} \cdot \mathrm{m}^{-3}$, tensile strength $600-900 \mathrm{~N} \cdot \mathrm{mm}^{-2}$ ).

At the first stage, mix-designs were adjusted and tested with respect to appropriateness of composition and rheological properties. For further testing, 5 mix-designs were selected (see Table 2). Tested specimens were made in the shape of a cube with side of $100 \mathrm{~mm}$. All mentioned properties of the tested concrete were always verified on 3 specimens.

\begin{tabular}{lccccc}
\hline \multicolumn{1}{c}{ Component / [kg.m -3 $^{-}$} & REC I & REC II & REC III & REC IV & REC V \\
\hline Blended cement CEM II/B-M (S-LL) 32.5 R & 320 & 300 & 300 & 300 & 300 \\
Sand 0-4 mm (quartz) & 953 & - & - & - & - \\
Coarse aggregate 4-8 mm (carboniferous graywecke) & 363 & - & - & - & - \\
Coarse aggregate 8-16mm (carboniferous graywecke) & 531 & - & - & - & - \\
Fine aggregate 0-4 mm (basalt) & - & 1162 & 1162 & 1162 & 1162 \\
Coarse aggregate 4-8 mm (basalt) & - & 340 & 340 & 340 & 340 \\
Coarse aggregate 8-16 mm (basalt) & - & 497 & 497 & 497 & 497 \\
Superplasticizer (1.8 \% m c $_{\text {chrysoFluid Optima } 208}$ & 5.8 & 5.4 & 5.4 & 5.4 & 5.4 \\
Water & 174 & 163 & 163 & 163 & 163 \\
W/C ratio & 0.54 & 0.54 & 0.54 & 0.54 & 0.54 \\
PP fibers A & - & - & 1 & - & - \\
PP fibers B & - & - & - & - & 0.6 \\
Cellulose fibers UltraFiber 500 Buckeye & - & - & - & - & 0.45 \\
\hline
\end{tabular}




\section{RESULTS AND DISCUSSION}

Physical-mechanical properties of specimens tested before and after thermal load were determined (density of hardened concrete, compressive strength). Summary of compressive strength and density of specimens made from specified mixture before and after thermal load can be seen in Table 3, Table 4 and Figure 1.
Surfaces of tested specimens exposed to thermal load were analyzed and percentage of damage was determined using AutoCAD software. Percentage of damage for thermal load to $900^{\circ} \mathrm{C}$ is shown in Table 5 and Figure 2. Initial photographs are in the part A of Figure 2, images in the part B show damage of surface highlighted in AutoCAD. An example of spalling on the concrete surface is presented in Figure 3.

Table 3 Compressive strength $\mathrm{f}_{\mathrm{cc}}[\mathrm{MPa}]$ of hardened concrete after 7 and 28 days in standard conditions and after thermal load.

\begin{tabular}{lcccccc}
\hline \multirow{1}{*}{ Mixture } & \multicolumn{5}{c}{ Compressive strength $\mathbf{f}_{\text {cc }}[\mathbf{M P a}]$} \\
\cline { 2 - 7 } & $\mathbf{7}$ days & $\mathbf{2 8}$ days & $\mathbf{2 0 0}^{\circ} \mathbf{C}$ & $\mathbf{4 0 0}^{\circ} \mathbf{C}$ & $\mathbf{6 0 0}^{\circ} \mathbf{C}$ & $\mathbf{9 0 0}{ }^{\circ} \mathbf{C}$ \\
\hline REC I & 29.0 & 41.8 & 40.2 & 37.5 & 35.6 & 9.3 \\
REC II & 21.6 & 34.3 & 33.4 & 29.8 & 24.4 & 10.1 \\
REC III & 24.4 & 38.0 & 35.4 & 32.5 & 31.7 & 14.4 \\
REC IV & 21.3 & 36.4 & 32.9 & 30.3 & 28.9 & 11.9 \\
REC V & 25.1 & 39.4 & 36.5 & 34.9 & 30.2 & 12.7 \\
\hline
\end{tabular}

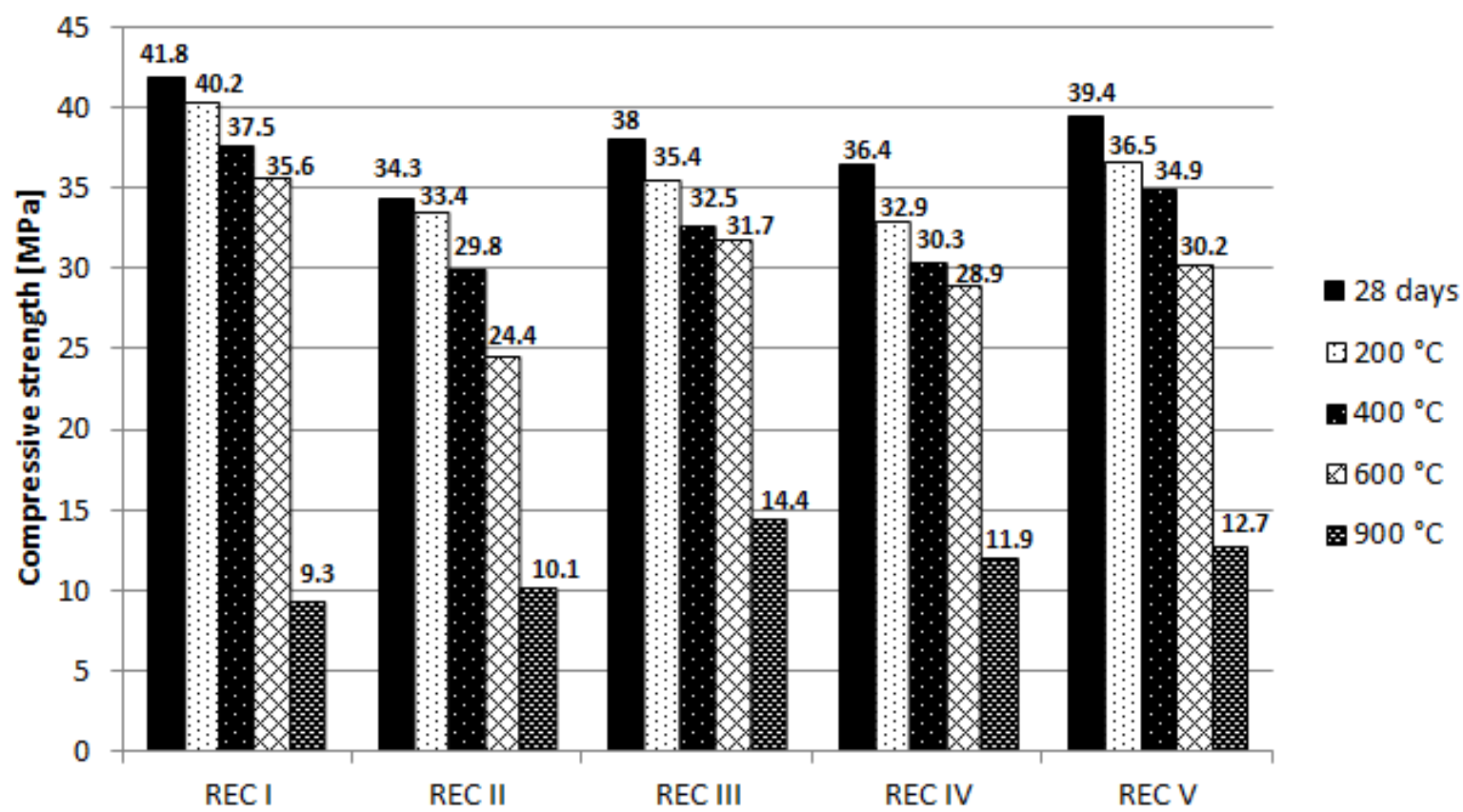

Fig. 1 Graphic comparison of compressive strength of hardened concrete before and after thermal load.

Table 4 Density of hardened concrete after 7 and 28 days in standard conditions and after thermal load.

\begin{tabular}{lcccccc}
\hline \multicolumn{1}{c}{ Mixture } & \multicolumn{6}{c}{ Density of hardened concrete D $\left[\mathbf{k g} / \mathbf{m}^{3}\right]$} \\
\hline & $\mathbf{7}$ days & $\mathbf{2 8}$ days & $\mathbf{2 0 0}{ }^{\circ} \mathbf{C}$ & $\mathbf{4 0 0}^{\circ} \mathbf{C}$ & $\mathbf{6 0 0}^{\circ} \mathbf{C}$ & $\mathbf{9 0 0}{ }^{\circ} \mathbf{C}$ \\
\cline { 2 - 7 } REC I & 2360 & 2350 & 2260 & 2250 & 2210 & 2170 \\
REC II & 2490 & 2470 & 2410 & 2380 & 2320 & 2300 \\
REC III & 2500 & 2510 & 2450 & 2410 & 2380 & 2350 \\
REC IV & 2490 & 2470 & 2410 & 2380 & 2360 & 2330 \\
REC V & 2500 & 2490 & 2420 & 2370 & 2370 & 2350 \\
\hline
\end{tabular}


REC I
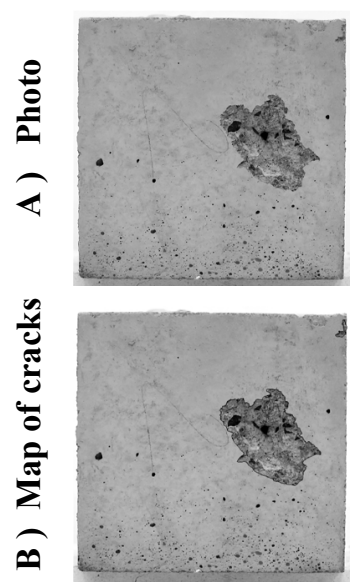

REC II
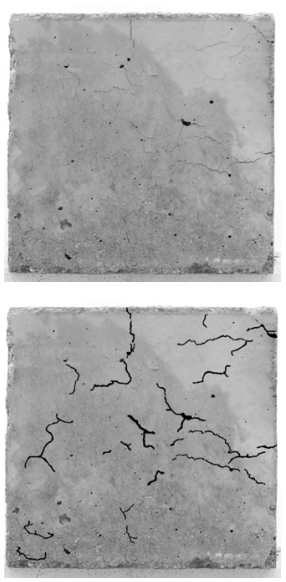

REC III
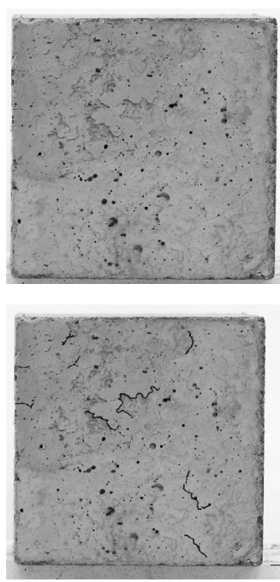

REC IV
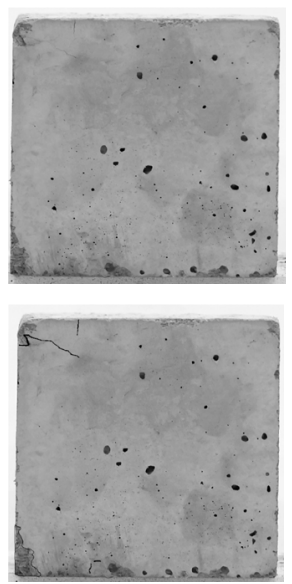

REC V
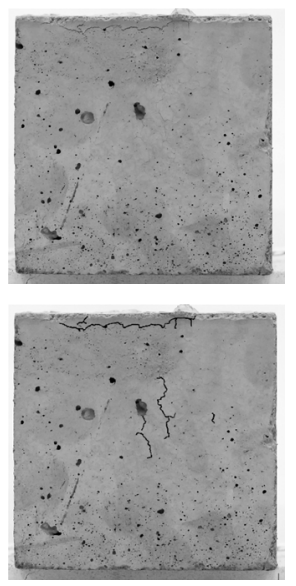

Fig. 2 Indication of failures on the surface of tested specimens after thermal load to $900{ }^{\circ} \mathrm{C}(\mathrm{A}-$ photo, B - indication by AutoCad software).

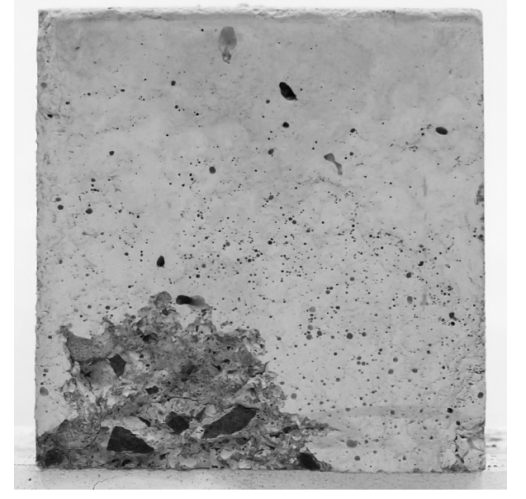

Fig. 3 An example of spalling on the concrete surface (mix-design REC I at temperature $400^{\circ} \mathrm{C}$ ).

Examination of compressive strength values before and after thermal load showed that mix-designs with components selected for good fire resistance clearly showed the least drop of compressive strength - in particular mix-design REC III with basalt and polypropylene fibers $\mathrm{A}$, where compressive strength after thermal load to $900{ }^{\circ} \mathrm{C}$ decreased down to $40 \%$ of the value measured before thermal load.

On the contrary (as expected), mix-design REC I with quartz and greywacke without any enhancing components was least resistant to high temperature. Compressive strength for mix-design REC I after thermal load to $900{ }^{\circ} \mathrm{C}$ reached only $20 \%$ of the value of compressive strength before thermal loading (see Fig. 1).

Mix-design REC I with quartz and greywacke aggregates with no components enhancing fire resistance showed the most significant changes of
Table 5 Percentage of cracks area after thermal load to $900^{\circ} \mathrm{C}$.

\begin{tabular}{lc}
\hline \multicolumn{1}{c}{ Mixture } & Percentage of cracks area [\%] \\
\hline REC I & 7.9 \\
REC II & 2.5 \\
REC III & 0.6 \\
REC IV & 1.6 \\
REC V & 0.5 \\
\hline
\end{tabular}

appearance. Spalling occurred after thermal load to temperatures of $400{ }^{\circ} \mathrm{C}$ (see Fig. 3), $600{ }^{\circ} \mathrm{C}$ and $900{ }^{\circ} \mathrm{C}$ for mix-design REC I. No other mix-design showed these phenomena in such extent.

Mix-design REC II, with basalt aggregate without addition of fibers, showed the second largest visual surface changes in the form of cracks. REC II showed the most significant decrease of compressive strength after thermal load for mix-designs with basalt aggregates (REC II - REC V). For example, the compressive strength after thermal load to $900{ }^{\circ} \mathrm{C}$ decreased down to $30 \%$ of the value measured before thermal load (REC II).

Combination of fibers and basalt aggregate (mixdesigns REC III, REC IV, REC V) had positive effect compared to mixtures only with basalt aggregate (see Table 5). Addition of polypropylene (REC III, REC IV) and cellulose fibers (REC V) ensured better cohesion of surface and prevented formation of cracks in concrete. Indication of failures on the surface of tested specimens after thermal load to $900{ }^{\circ} \mathrm{C}$ is shown in Figure 3. Surface of tested specimens exposed to lower temperatures $\left(600{ }^{\circ} \mathrm{C}, 400{ }^{\circ} \mathrm{C}\right.$ and $200{ }^{\circ} \mathrm{C}$ ) were also examined, however, no cracks caused by thermal load were observed. 
Changes of density of concrete after thermal load were observed, too (see Table 4). The lowest density reaches mix-design REC I with aggregates quartz and greywacke and higher content of cement and water (see Table 2). All mix-designs (REC I - REC V) showed a decrease of density after thermal load. Decreases are caused mainly by loss of water. Heating leads to loss of following water classes: capillary water (at temperatures between 20 and $80{ }^{\circ} \mathrm{C}$ ) and physically bound water (at about $200{ }^{\circ} \mathrm{C}$ ). The largest decline of density after heating to $200{ }^{\circ} \mathrm{C}$ demonstrates mix-design REC I, which corresponds to a higher content of water and cement per $1 \mathrm{~m}^{3}$ (Table 2). The decreases of density for mix-designs REC II - REC V with the same amount of water and cement are comparable.

Experiments performed by our research team and presented in this article follow the studies focused on monitoring of the behaviour of the cement matrixes of various types of cement (Khandaker, 2006), (Savva, 2005) and aggregate (Khoury, 1992) at high temperatures. Information from these foreign research works were used to select the appropriate type of aggregate and cement. The selection of raw materials for experiments specified in this article is oriented to the resources available in the Czech Republic with regard to the subsequent use of knowledge for the proposal of concrete design with cement binder of higher resistance against action of high temperatures for concrete structures in the Czech Republic. Besides the possibility of increasing the resistance of cement concrete against high temperatures using polypropylene fibers (Hager and Tracz, 2009), effect of cellulose fibers is studied as well, although at present cellulose fibers are not usually utilized for increasing the resistance of concrete to high temperatures neither in the Czech Republic nor in the Europe.

\section{CONCLUSIONS}

Paper describes preparation of mix-designs with higher resistance to high temperatures and testing of physical-mechanical properties of tested specimens exposed to thermal load of $200{ }^{\circ} \mathrm{C}, 400{ }^{\circ} \mathrm{C}, 600{ }^{\circ} \mathrm{C}$ and $900{ }^{\circ} \mathrm{C}$. Changes of density, compressive strength and occurrence of cracks of individual mix-designs were observed. Density changes correspond to results of previous experiments achieved by authors of the paper (Bodnárová et al., 2010) and were confirmed also by other researchers (Vydra et al., 2001). Mixdesign REC III with basalt aggregates and polypropylene fibers was evaluated as the most resistant to high temperatures $\left(900{ }^{\circ} \mathrm{C}\right)$ among proposed mixtures. The compressive strength of mixdesign REC III after thermal load to $900{ }^{\circ} \mathrm{C}$ was 14.4 $\mathrm{MPa}$ (maximum achieved value), which is $40 \%$ of the value measured before thermal load. This mixture demonstrated only $0.6 \%$ of cracks area after thermal load to $900{ }^{\circ} \mathrm{C}$. Minimum surface defect was observed in mix-designs with combination of fibers and basalt aggregate (mix-designs REC III, REC IV and REC V). It seems, that mix-design of concrete resistant to fire should be prepared with addition of polypropylene fibers that proved reduction of spalling after exposition of concrete to high temperature.

The results of the experimental work confirm that polypropylene and cellulose fibers and basalt aggregate (from locality in Czech Republic) have positive influence on enhancing the temperature resistance of concrete. Therefore, they can be recommended for constructions like road tunnels, which are likely to be exposed to extreme thermal load.

\section{ACKNOWLEDGEMENT}

This article was written in connection with project Institute of clean technologies for mining and utilisation of raw materials for energy use, reg. no. CZ.1.05/2.1.00/03.0082, which is supported by the Research and Development for Innovations Operational Programme financed by the Structural Founds of the Europe Union and the state budget of the Czech Republic. The outcome has been achieved with the financial support of project GAČR P104/12/1988, ,Study of interactions of components of cementitious composites exposed to high temperatures", project of Brno University of Technology, Czech Republic Project No. 22209 and RVO: 68145535.

\section{REFERENCES}

Bodnarova, L., Hela, R. and Valek, J.: 2010, Properties of fibre concrete after various degrees of heat loading. Concrete under Severe Conditions, Environment and loading. London, UK, Taylor\&Francis Group, 561567.

Ellis, P.R.: 1999, Analysis of mortars (to include historic mortars) by differential thermal analysis. International RILEM Workshop on Historic Mortars: Characteristics and Tests. Editor(s): P. Bartos, C. Groot and J. J. Hughes. 133-147.

EN 14647: Calcium aluminate cement - Composition, specifications and conformity criteria

EN 1992-1-2: Eurocode 2: Design of concrete structures Part 1-2: General rules - Structural fire design

Feldman, F.R. and Sereda, P.J.: 1968, A model for hydrated Portland cement paste as deduced from sorptionlength change and mechanical properties, Materials and Structures, 509-519.

Fib Bulletin 38: 2007, Fire design of concrete structures: materials, structures and modelling. FIB. State-of-art report. 106 pp., April 2007.

Hager, I. and Tracz, T.: 2009, Influence of elevated temperature on selected properties of high performance concrete modified with the addition of polypropylene fibres. Cement wapno beton, 14, Issue 1, January 2009.

Hanzlíček, T. and Perná, I.: Thermal resistance of foamed fluidized bed ashes. Acta Geodyn. Geomater., 8, No. 2 (162), pages 115-122, 2011.

Khandaker, M.: 2006, Anwar Hossain. High strength blended cement concrete incorporating volcanic ash: Performance at high temperatures. Cement and Concrete Composites, 28, Issue 6, July 2006, 535545 . 
Khoury, G.A.: 1992, Design of concrete for better performance in fire. Proceedings of the Institute of Mechanical Engineering Series, 121-127, Mechanical Engineering Publ., Bury St Edmunds.

Kodur, V.: 2008, Designing Concrete Structures for fire Safety, American Concrete Institute.

Meftah, F., Dal Pont, S. and Schrefler, B. A.: 2012, A threedimensional staggered finite element approach for random parametric modeling of thermo-hygral coupled phenomena in porous media. International journal for numerical and analytical methods in geomechanics, 36, April 2012, Issue 5, 574-596. DOI: $10.1002 /$ nag. 1017

Pistol, K., Weise, F. and Meng, B.: 2012, Polypropylene fibres in high performance concretes Mechanisms of action in the event of fire, Beton- und Stahlbetonbau, 107, Issue 7, July 2012, 476-483. DOI: $10.1002 /$ best.201200024

Savva, A, Manita, P. and Sideris, K.K.: 2005, Influence of elevated temperatures on the mechanical properties of blended cement concretes prepared with limestone and siliceous aggregates. Cement and Concrete Composites, 27, Issue 2, February 2005, 239-248. DOI: 10.1016/j.cemconcomp.2004.02.013

Vydra, V., Vodák, F., Kapičková, O. and Hošková, Š.: 2001, Effect of temperature on porosity of concrete for nuclear safety structures. Cement and Concrete Research, 31(7),1023-1026.

DOI: $10.1016 / \mathrm{S} 0008-8846(01) 00516-6$

Xing, Zhi, Hebert, R. and Noumowe, A.: 2011, Influence of the nature of aggregates on the behaviour of concrete subjected to elevated temperature. Cement and concrete research, 41, no 4, 392-402. DOI: 10.1016/j.cemconres.2011.01.005

Zeiml, M., Lackner, R., Leithner, D and Eberhardsteiner, J.: 2008, Identification of residual gas-transport properties of concrete subjected to high temperatures. Cement and concrete research, 38, Issue 5, May 2008, 699-716. DOI: 10.1016/j.cemconres.2008.01.005 